\title{
An Overview of the Problems Facing the Automobile Industry in Ghana
}

\author{
Mamudu Hamidu ${ }^{1}$, Alfred Sarbah ${ }^{2}$ \\ ${ }^{1}$ Electrical/Electronic Engineering Department, Kumasi Technical University, Kumasi, Ghana \\ ${ }^{2}$ Department of Management Studies, Kumasi Technical University, Kumasi, Ghana \\ Email address: \\ drsennet@gmail.com (M. Hamidu), mamudu.hamidu@kstu.edu.gh (M. Hamidu), sarbah@yahoo.com (A. Sarbah)

\section{To cite this article:} \\ Mamudu Hamidu, Alfred Sarbah. An Overview of the Problems Facing the Automobile Industry in Ghana. American Journal of \\ Management Science and Engineering. Vol. 2, No. 2, 2017, pp. 23-28. doi: 10.11648/j.ajmse.20170202.11
}

Received: September 4, 2016; Accepted: January 13, 2017; Published: April 11, 2017

\begin{abstract}
The automobile industry is faced with a lot of challenges. These challenges affect the both the environment and economic distribution of resources in Ghana. This research employs a purposive sampling technique in collecting views of automobile operators in Ghana to establish a general overview of problems facing the sector. In this study, it is estimated that $75 \%$ of respondent's vehicle is powered by Diesel and only 5\% of respondent's vehicle is moved by gas. Making fossil fuel the most predominantly use means for vehicle operation in Ghana. The research identifies that the use of fuel and maintenance are challenging problems in vehicle operation. It is found that as the cost of fuel increases, the expenditure also increases with a marginal fare increase. It is established that, about $90 \%$ of the respondents asserted that it was very expensive hence they have being looking for other means such as the conversion of petrol/diesel to gas system. However the gas also poses another challenge with constant shortage. It was also estimated that the cost of maintenance is at a modal cost of GHC 250 per annum with modal number of maintenance in a year being 12 .
\end{abstract}

Keywords: Automobile Industry, Environmental Pollution, Fuel Consumption, Maintenance, Challenges

\section{Introduction (Background)}

The increasing demand for automobiles such as cars, trucks alongside with long vehicles is closely linked with the progressive economic development of the country. From this, it has become so obvious that the increasing vehicular usage has thrown a new challenge to city and development managers of the country. This is because the growing usage of the current form of vehicles has contributed significantly to the increasing deterioration of the environment through atmospheric pollution. Automobile is made of complex product that consists of a number of systems and material types [10].

According to the Ghana Driver Vehicle and Licensing Authority, it has registered increasing number of vehicles from the period of 2000 to 2009 [7] as shown in figure 1 . The increase usage of combustion vehicles according to [2] accounted for the high levels of pollution in the urban centers of the country.

A study conducted by Environmental Protection Agency
(EPA) (2003) on monitoring the air quality at twelve (12) sites in Accra indicated that emission from combustion vehicles constitutes a major source of environmental pollution [1]. Vehicular emission accounts for about $90 \%$ of all atmospheric lead emissions and is the largest source of human exposure to lead emission in the urban centers of Ghana [6].

The automobile industry has being up to many challenges in Ghana even though Vehicles today are vastly superior to and more reliable than those produced just a decade ago in terms of economy, safety, comfort, functionality, and performance [9]. These challenges are of diverse effect to both the operators and their customers. It takes the form of both economic and environmental effects. Therefore this research looks at the perspective of the vehicles in the automobile industry and how it impact on their operations.

The cost of fueling and maintenance of combustion engine vehicle (lubrication and cleaning filters) is a major challenge. These challenges will be factored in the design of proposed car to be designed. 


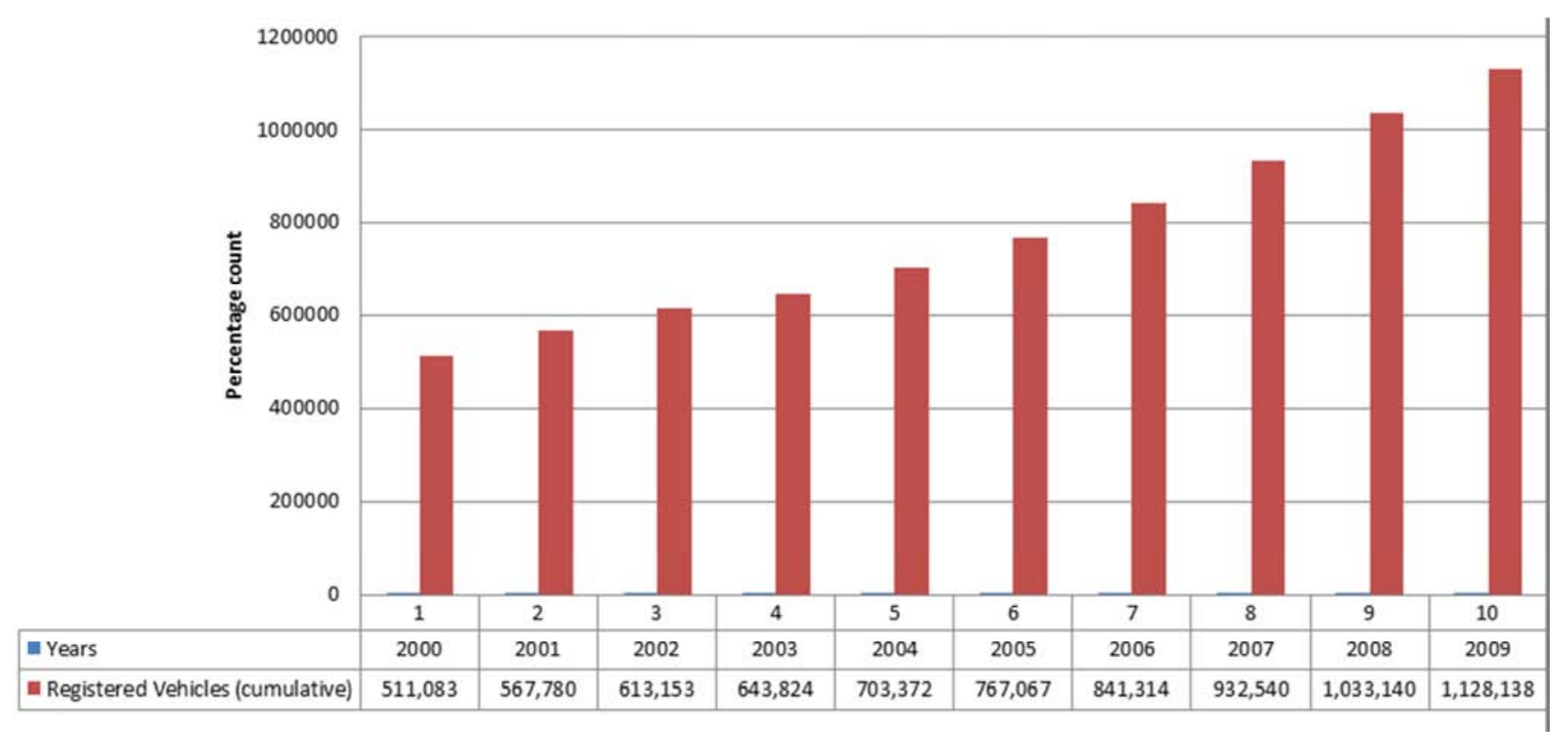

Source: Nerquaye-Tetteh, EPA (2011).

Figure 1. The number of vehicle registered from 2001 to 2009.

\subsection{Environmental Pollution}

Emissions from combustion vehicles constitutes various types of chemical compounds such as Particulate Materials (PM), Carbon Monoxide (CO), Carbon Dioxide $\left(\mathrm{CO}_{2}\right)$, Hydrocarbons Oxides of Nitrogen (NOx), Silicon dioxide $\left(\mathrm{SO}_{2}\right)$, Lead $(\mathrm{Pb})$, Platinum $(\mathrm{Pt})$, Copper $(\mathrm{Cu})$, Zinc $(\mathrm{Zn})$, Particulates and other toxic pollutants.

In 2003 the EPA designed a mechanism to monitor the

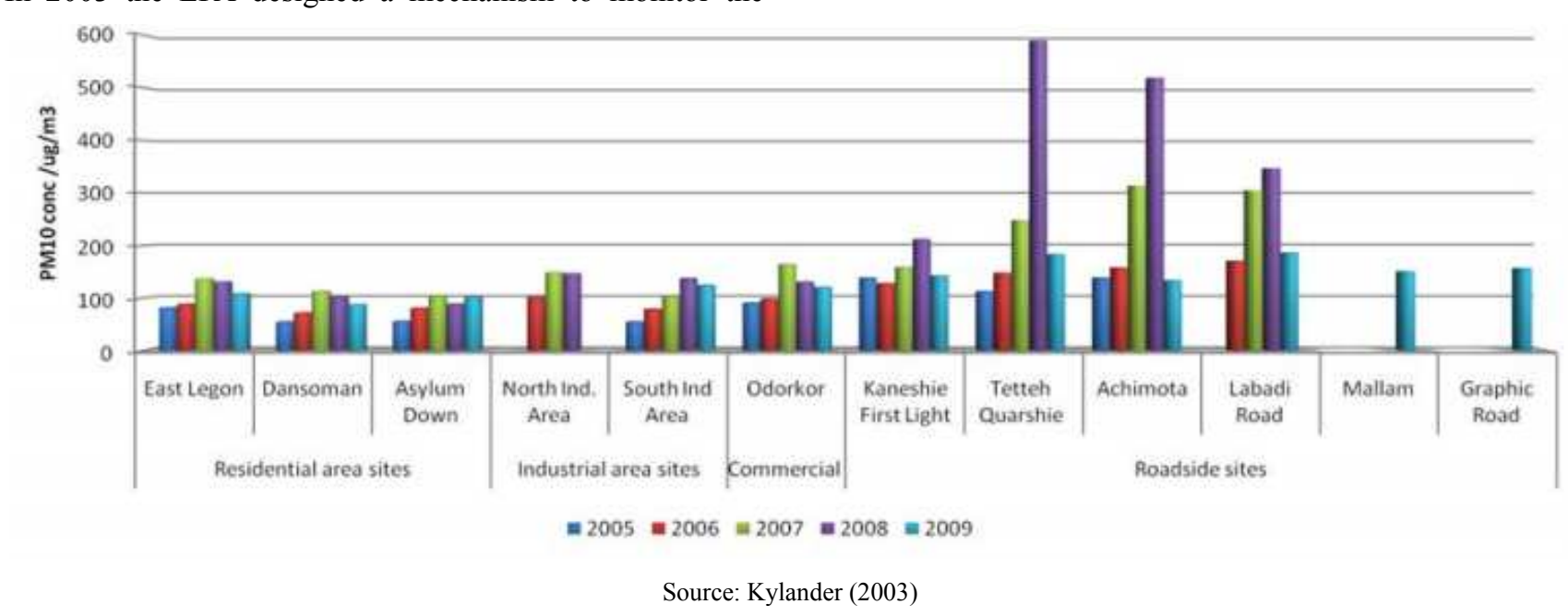

Figure 2. PM levels for the period 2005 -2009 from 12 sites.

\subsection{Negative Effects of Combustion Emissions on the Environment}

Vehicular emission accounts for about $90 \%$ of all atmospheric lead emissions and is the largest source of human exposure to lead emission in the urban centers of Ghana [6]. In most of the times, platinum $(\mathrm{Pt})$ is emitted in the form of nanoparticles which are part of aluminum oxide. level of emissions on our roads. Air quality monitoring systems were place at 12 sites in Accra. The results showed that the six roadside sites produced the highest PM10 pollutant levels for the period 2005-2009 compared with the residential, commercial and industrial sites as shown in figure 2. This finding confirmed the fact that emissions from combustion vehicles constitute high levels of environmental pollutants. 
vehicle very challenging. Additionally, the cost of maintaining the vehicle is another bane of the combustion engine. Aside the cost of fueling the engine, one also needs to maintain the vehicle by lubricating it regularly with other lubricants and cleaning the filters. Also, emits unfriendly gases which degrade the environment.

\section{Methods and Materials}

\section{Data collection Method}

The research uses purposive simple random sampling technique. This approach was used to in the form of stratify way to help provide opportunity for considering different aspect of the problem [8].

Under the research schedules, eighty-six (86) data was collected using both close and open ended formats out of the one hundred and twenty (120) administered through nonprobabilistic sampling. The research schedule consisted of both open-ended and close-ended. In other to explore the various vehicle technology and the factors affecting the automobile industry in Ghana, the research looks at the players. In view of this, various transport stations were contacted with their mechanics, drivers and mates. The data collection were stratified by randomized means with Opoku Agyemang (O.A.) Transport services having 10 respondents, V.I.P Station constituting 20, Ford Station presenting 20, 15 from Afiakobi station, Metro Mass Transport Ltd. (10), VVIP (5), Adihye station (Achamfour) making up 14, and the Anloga Junction Taxi rank Lorry station recording 10 respondents.

\section{Findings}

\subsection{Background characteristics of Respondents}

The study assessed the background characteristics of the respondents. It was found that $98 \%$ of the respondents were males. It was also found that almost $73 \%$ of the respondents had up to JHS level of formal education with about $2.4 \%$ been about 60 years as shown in figure 3

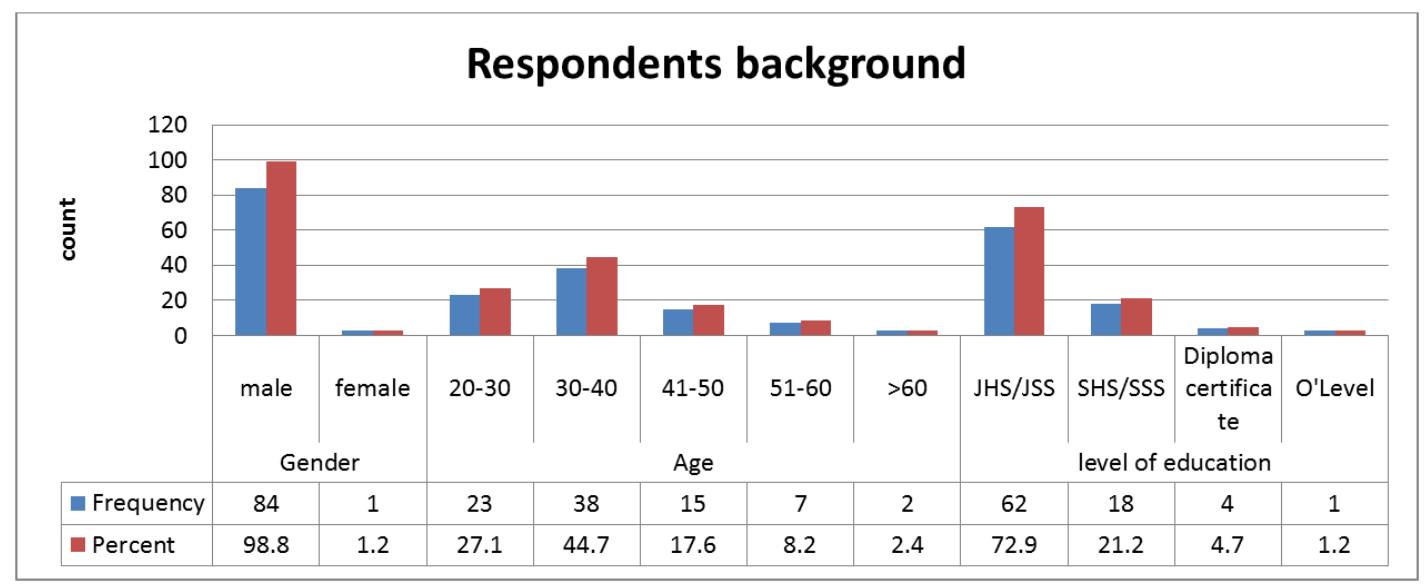

Figure 3. Respondents' gender, age and educational levels.

\subsection{Respondents Transport Companies/Unions}

Of the respondents studied, it was clear that $44 \%$ to do not belong to any known company. Also, about $22 \%$ belonged to VIP whiles only $1.4 \%$ each of the respondents belonged to the Ford Company, Cool family, and Ghana Express.

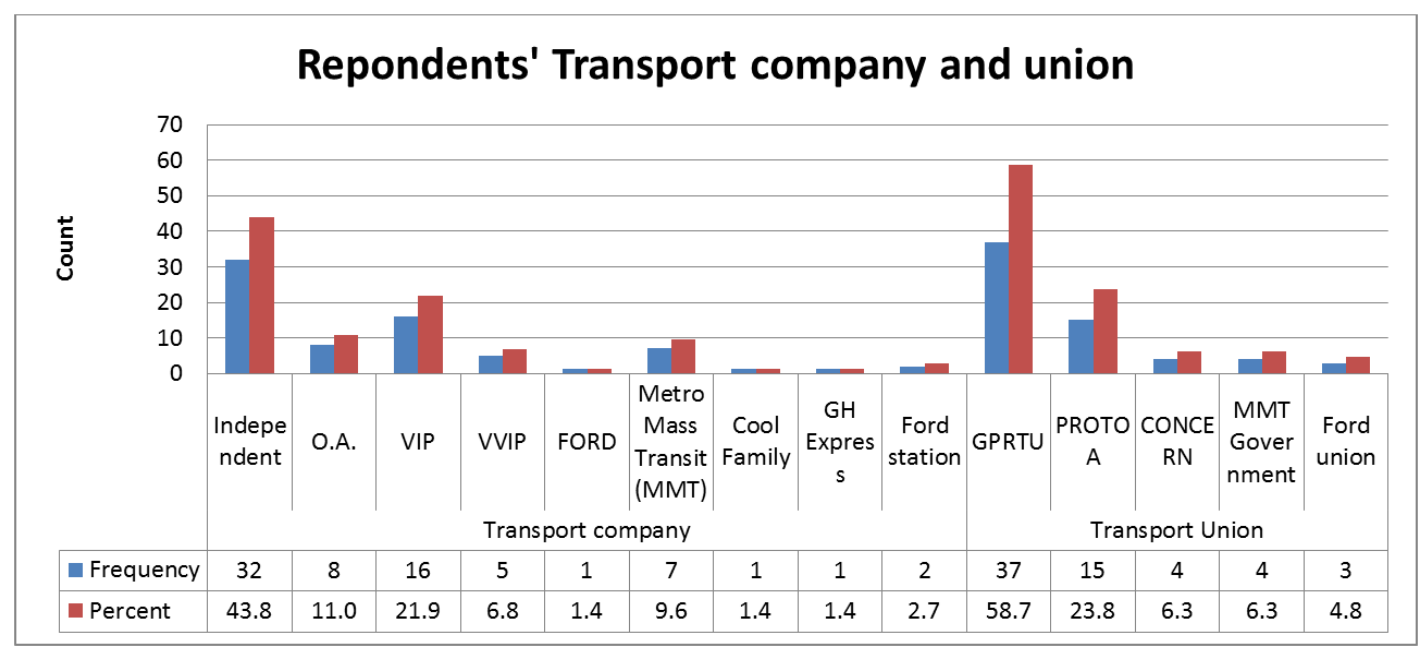

Figure 4. Names of company and belonging transport unions. 
In the same vein, about $59 \%$ of the respondents belonged to the GPRTU as a union whiles only about $5 \%$ belonged to the Ford union as shown in figure 4.

\subsection{Type of Fuel Consumed and Cost of Fuel Consumed by Vehicle}

The study unearthed that $75 \%$ of respondent's vehicle is powered by Diesel and only $5 \%$ of respondent's vehicle is moved by gas as shown in figure 5 .

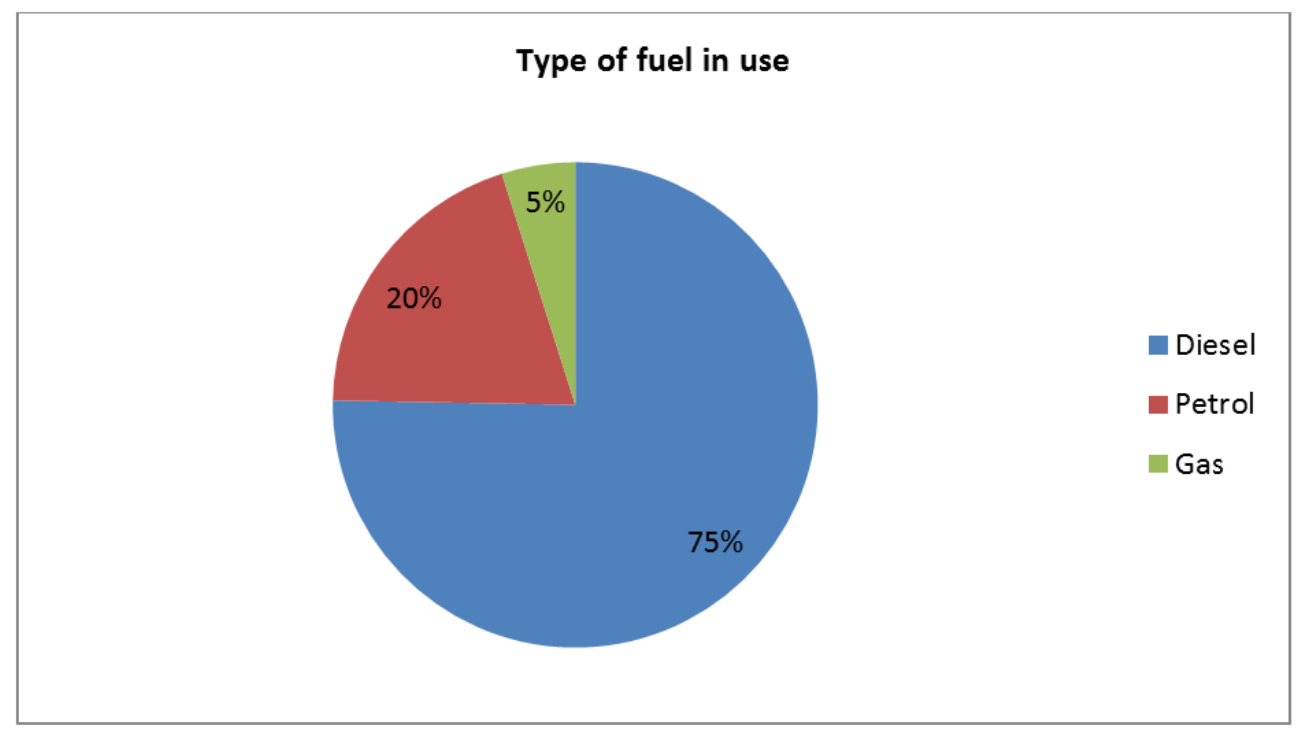

Figure 5. Types of fuel in use.

The study assessed the cost of fuel consumed by respondents current vehicle used in running his/her business. It was found that the modal litre consumed per week was 22.50 whilst the modal cost per week was 600.00 GHC as shown in table 1 .

Table 1. Type of fuel consumed and cost of fuel consumed by vehicle.

\begin{tabular}{llllll}
\hline parameters & liter of fuel per week & cost of fuel per week & cost of fuel per month & liters of fuel per month & Liters for operation \\
\hline Mean & 465.9783 & 36779.4783 & 1901.3776 & 648.7100 & 158.1562 \\
Median & 142.5000 & 780.0000 & 1500.0000 & 205.0000 & 36.0000 \\
Mode & $22.50^{\mathrm{a}}$ & $600.00^{\mathrm{a}}$ & $160.00^{\mathrm{a}}$ & 180.00 & 36.00 \\
\hline
\end{tabular}

a. Multiple modes exist. The smallest value is shown

The average cost of 600 GHC per week was perceived to be expensive as about $90 \%$ of the respondents asserted that it is expensive and they finding ways to avoid such an extreme cost on their businesses. This was supported by the fact that about $91 \%$ of the respondents said they will want to avoid such a cost as shown in figure 6 .

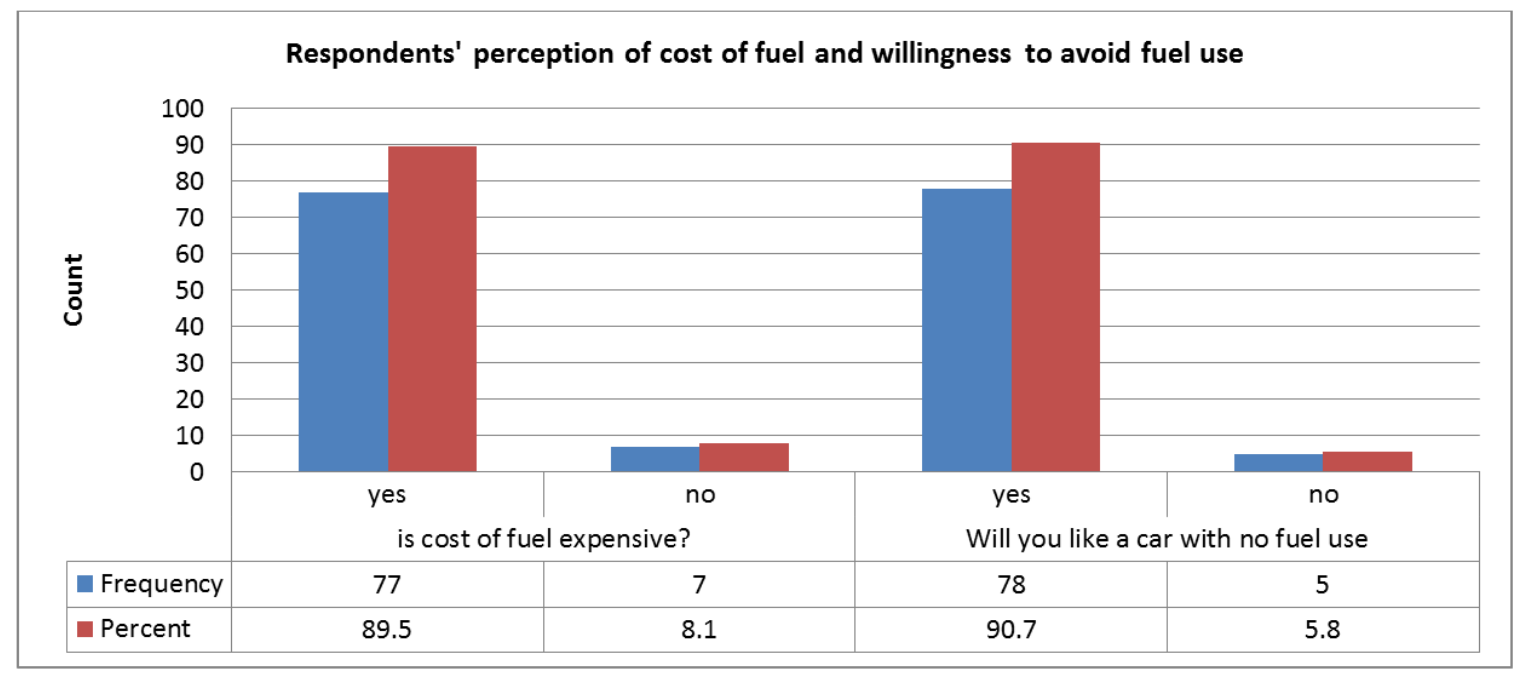

Figure 6. Perception of use of fuel. 


\subsection{Number of Maintenance in a Year and Expenditure on Maintenance}

The study also sought to understand the number of maintenances carried out by respondents on their vehicles in a year and the cost of maintenance in a year. It was observed that on the average the respondents carry out about 16 times in a year. In the same vein the cost of maintenance was about GHC1,580 in a year which they said was high as shown in table 2 which excludes some minor cost.

Table 2. Summary of number of times and cost of maintenance in a year.

\begin{tabular}{lll}
\hline & $\begin{array}{l}\text { Number of maintenance } \\
\text { in a year }\end{array}$ & $\begin{array}{l}\text { Cost of engine } \\
\text { maintenance in a year }\end{array}$ \\
\hline Mean & 16.1691 & 1579.6415 \\
Median & 12.0000 & 1040.0000 \\
Mode & 12.00 & $250.00^{\mathrm{a}}$ \\
Minimum & 1.00 & 1.00 \\
Maximum & 48.00 & 9600.00 \\
\hline
\end{tabular}

a Multiple modes exist. The smallest value is shown

\section{Discussion}

In an attempt to solve the challenges facing the automobile industry in Ghana, this research implored a problem based assessment means to help understand the real ideas and problem affecting the transport sector (drivers). However, upon embarking on a purposive simple random sampling technique on about eight different transport stations in the Kumasi metropolis, about eight six (86) respondents were reached to obtain their views in a future automobile design.

Among the sampled size, about $99 \%$ of the respondents were men and about $45 \%$ of them being the ages between thirty and forty years. This shows that the industry has much youth dominance. Therefore much study could be of utmost desirable in different dimensions. In the same vein, the educational level has about $72 \%$ of the respondents having their highest level of education been Junior Secondary School (JSS) or the Junior High School (JHS). Therefore the questions to ask will probably be, the level of understanding to adapt to emerging dimensions of various technologies and also the rules and regulations on the road, the level of education did have less significance on the use of automobile.

Despite these findings, it was found that, about $44 \%$ of the respondents operate independently without being employed by any transport company. About $2 \%$ of them being family controlled operations. In the study, almost the entire vehicle belongs to a transport union, with about $59 \%$ belonging to Ghana Private Road Transport Union (GPRTU).

In terms of the main challenges facing the industry, the research was focused on the fuel used, maintenance, and vehicle operation. It was found that as the cost of fuel increases, the expenditure also increases with a marginal fare increase. This cost also affects price for maintenance and other related expenses. In response to this, about $90 \%$ of the respondents asserted that it was very expensive hence they have being looking for other means such as the conversion of petrol/diesel to gas system. However the gas also poses another challenge with constant shortage. It was estimated that the cost of maintenance is at a modal cost of GHC250 per annum with modal number of maintenance in a being 12 . In this view, there is the need to open a new chapter in future on how new automobile design will provide the assistance to the challenge of both socio-economic background.

\section{Conclusion}

In the eave of the influx of various automobile brands in the Ghanaian market, there have been multifaceted challenges that have direct effect on socio-economic and environment settings. This research looking at the commercial public transport of the automobile industry identifies that the sector has several groups of unions with the main aim of providing service to the general public and also gaining purchasing power from the government.

The mostly used fuel is assessed with all been crude oil product. The highly used fuel has been diesel. It is realized that fuel has been constant worry on the industry as the effect ranges from cost to maintenance. Therefore automobile operators would have wished there would be an alternative.

In view of this outcome, the research also established that, the influx of the automobiles in Ghana has possible effect on the automobile industry. The reasons been the increase in fuel price causing marginal positive correlation between the increase in maintenance per year depending on the brand in use and the nature of road against the period of usage of vehicle.

\section{References}

[1] Esi Nerquaye-Tetteh, EPA (2011). Vehicle emission reduction programme in Ghana. Available: [http://www.unep.org/transport/pcfv/PDF/Abidjan_9GHANA. pdf]. Accessed on13/12/2015

[2] Kylander, M. E., Sebastien R., Gregory, M. M., and Kwesi, A. (2002). Impact of automobile emissions on the levels of platinum and lead in Accra, Ghana. Available: [http://pubs.rsc.org/en/content/articlehtml/2003/em/b211736c]

[3] Lustig, S., Zang, S., Michalke, B., Schramel, P. and Beck, (1996). W. Sci. Total Environ, USA.

[4] Artelt, S., Kock, H., König, H. P., Levsen K. and G. Rosner, (1999). Atmos. Environ., pp 33.

[5] Luna, J. C. Saenz and J. Santamaria, Sci. Total Environ., 2002, 296, 199 C. Wei and G. M. Morrison, Anal. Chim. Acta, 1994, 284,587

[6] Kylander, M., Rauch, S.; Morrison, G. M., and Andam, K. (2003). Impact of Automobile Emissions on the level of Platinum and Lead in Accra. Available on: [https://www.docphin.com/research/articledetail/17236019/PubMedID-12619761/Impact-of-automobileemissions-on-the-levels-of-platinum-and-lead-in-AccraGhana]. Accessed on 13/10/2015 
[7] Driver and Vehicle Licensing Authority [DVLA]. (2010). National fleet statistics, Ghana.

[8] Kathori, C. R. (2004) Research Methdology, Methods and Techniques. New Age International (P) Limited, Publishers, New Delhi.

[9] Booz:Allen \& Hamilton. (1999). Challenges Facing the Global Automotive Industry. VOL. 1 ISSUE 1 Available on: [http://www.boozallen.com/content/dam/boozallen/media/file/ Challeng.pdf] Accessed on 9/01/2017

[10] Sutherland, J., Gunter, K., Allen, D., Bauer, D., Bras, B., Gutowski, T.,... \& Wolff, E. (2004). A global perspective on the environmental challenges facing the automotive industry: state-of-the-art and directions for the future. International Journal of Vehicle Design, 35 (1), 86-110. 